\title{
IMAGE ANALYSIS CHARACTERIZATION OF HIGHLY ORIENTED FREEZE-DRYING POROUS MATERIALS
}

\author{
SILVIA BLACHER ${ }^{1,3}$, VÉRONIQUE MAQUET ${ }^{2,3}$, ROBERT JÉRÔME ${ }^{2,3}$ AND JEAN PAUl PIRARD ${ }^{1}$ \\ ${ }^{1}$ Department of Chemical Engineering, ${ }^{2}$ Center for Education and Research on Macromolecules, ${ }^{3}$ Interfacultary \\ Center for Biomaterials, University of Liège, Sart-Tilman, B6, 4000 Liège, Belgium \\ e-mail: silvia.blacher@ulg.ac.be \\ (Accepted February 15, 2002)
}

\begin{abstract}
Image analysis has been used as a potential tool for the characterization of the texture of ultramacroporous foams prepared by freeze-drying. It has been shown that this technique actually provides valuable information on the structure of this kind of material. Image analysis of SEM micrographs of transverse sections at two different magnifications gave information on both the macroporosity $(10 \mu \mathrm{m}<$ width $<100 \mu \mathrm{m})$ and ultramacroporosity (width $>100 \mu \mathrm{m}$ ). Moreover, the foam anisotropy has been determined by image analysis of longitudinal sections.
\end{abstract}

Keywords: foams, freeze-drying, image analysis, porous polymer.

\section{INTRODUCTION}

Porous polymer scaffolds are promising materials for tissue engineering because they offer a temporary environment for cell seeding and subsequent transplantation into the host (Maquet et al., 1997). The porosity and structure of these scaffolds are key characteristics for the success of this strategy. Pores larger than $10 \mu \mathrm{m}$ are essential for sustaining cell infiltration, whereas a pore smaller than $10 \mu \mathrm{m}$ contribute to cell attachment and create a large surface area for the growth of tissue layers. Some of us have shown that highly oriented porous scaffolds have a great potential as temporary implants for supporting axonal regeneration in case of lesioned rat sciatic nerve (Maquet et al., 2000) and spinal cord (Maquet et al., 2001). Mercury porosimetry is currently used to measure pore volume and pore size distribution of porous biomaterials. However, this technique is limited to pore size in the $7.5 \mathrm{~nm}-75 \mu \mathrm{m}$ range, and shrinkage of the sample due to mercury penetration under high pressure can lead to incorrect pore size distribution. In this study, image analysis is presented as a non-destructive method for the texture characterization of polymer foams prepared by the thermally induced phase separation of random poly( $\varepsilon$ caprolactone- $c o$-L-lactide) (PCLA) copolymers dissolved in dimethylcarbonate (DMC) and subsequent solvent sublimation. Image processing and measurement on two-dimensional transverse and longitudinal cross-sections of the polymer foams are implemented to investigate the influence of the cooling rate on the pore size distribution and pore morphology.

\section{MATERIALS AND METHODS}

Poly( $\varepsilon$-caprolactone-co-L-lactide) (PCLA 5:95) with a molecular weight of 275,000 was dissolved in $20 \mathrm{ml}$ of dimethylcarbonate in a $100 \mathrm{ml}$ round-bottom flask, under magnetic stirring overnight. The solution was frozen for two hours in one of the following cooling system, (i) liquid nitrogen $\left(-196^{\circ} \mathrm{C}\right)$ and (ii) dry ice/acetone $\left(-78^{\circ} \mathrm{C}\right)$. The solvent was then removed by vacuum sublimation by connecting the flask to a vacuum pump operating at $10^{-2}$ Torr. The system was kept frozen at $-10^{\circ} \mathrm{C}$ for a first drying period of $48 \mathrm{~h}$. The secondary drying was performed at $0^{\circ} \mathrm{C}$. The foam was finally vacuum dried at room temperature until a constant weight was reached. The foams were cut parallel and perpendicular to the surface and the respective transverse and longitudinal sections were sputtered with platinum for $120 \mathrm{sec}$ under an argon atmosphere. Samples were observed with a Jeol JSM$840 \mathrm{~A}$ at an accelerating voltage of $20 \mathrm{kV}$. SEM micrographs at 10 times and 100 times magnification, allowed the ultramacropores (ca. $100 \mu \mathrm{m}$ width) and the macropores (ca. $10 \mu \mathrm{m}$ width) to be analyzed by image analysis, respectively. Image treatment and statistic analysis were performed with a WorkStation Sun SPARC30, and the software 'Visilog 5.0' from Noesis. Images were digitized on a matrix of 
$1024 \times 1024$ pixels with 256 gray levels. Five images of different areas of the same sample were analyzed.

\section{RESULTS AND DISCUSSION}

Typical SEM micrographs of transverse and longitudinal sections for PCLA foams are shown in Figs. 1a-c. From the transverse sections, two levels of porosity can be observed: ultramacropores with diameter $\geq 100 \mu \mathrm{m}$ and macropores $(10-20 \mu \mathrm{m})$. Gray level image transformations and binary image processing of both transverse and longitudinal sections are schematized in Fig. 2.
It must be noted that most of these transformations are parameter dependent. As a rule, if all the images are digitized under the same conditions, parameters are fixed once and for all, and the image binary processing is then completely automatic. In this study, the processing parameters have been changed for each set of images, because of brightness and contrast variations. However, this approach could be refined using a less parameter dependent segmentation strategy based, for example, on the extraction of minima rather than on the use of thresholds. Figs. 1d$\mathrm{f}$ illustrate the result of filtering and binary image processing. Binary images illustrated in Figs. 1e and if take only the pore boundaries into account.
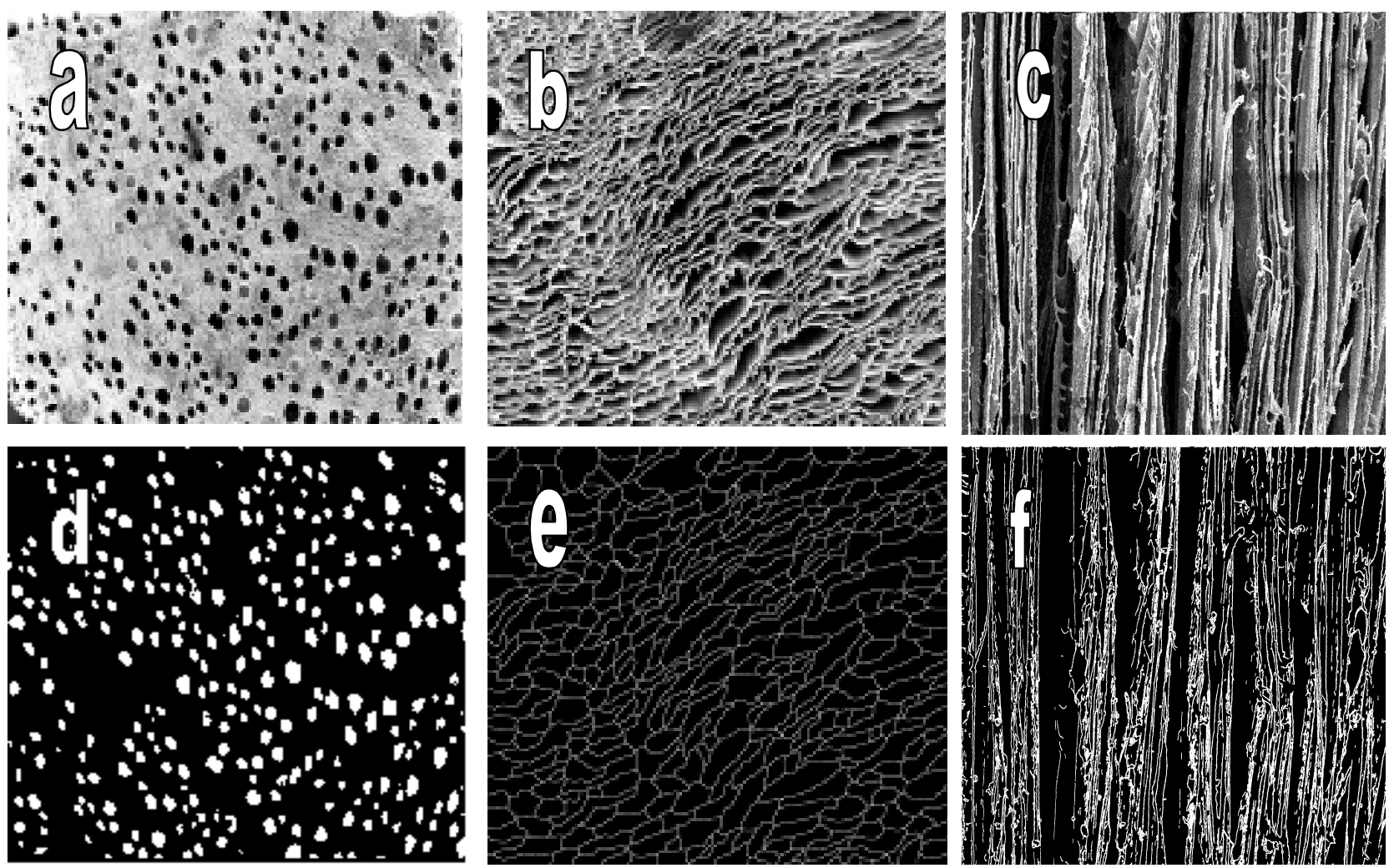

Fig. 1. Scanning electron micrograph of transverse $(a, b)$ and longitudinal $(c)$ cross-sections of PCLA foams at $\times 10(a)$ and $\times 100(b, c)$ original magnification. Extraction of the ultramacropores $(d)$, the macropores $(e)$ and the pore orientations $(f)$. 


\section{Original Image}

Processing image binarization

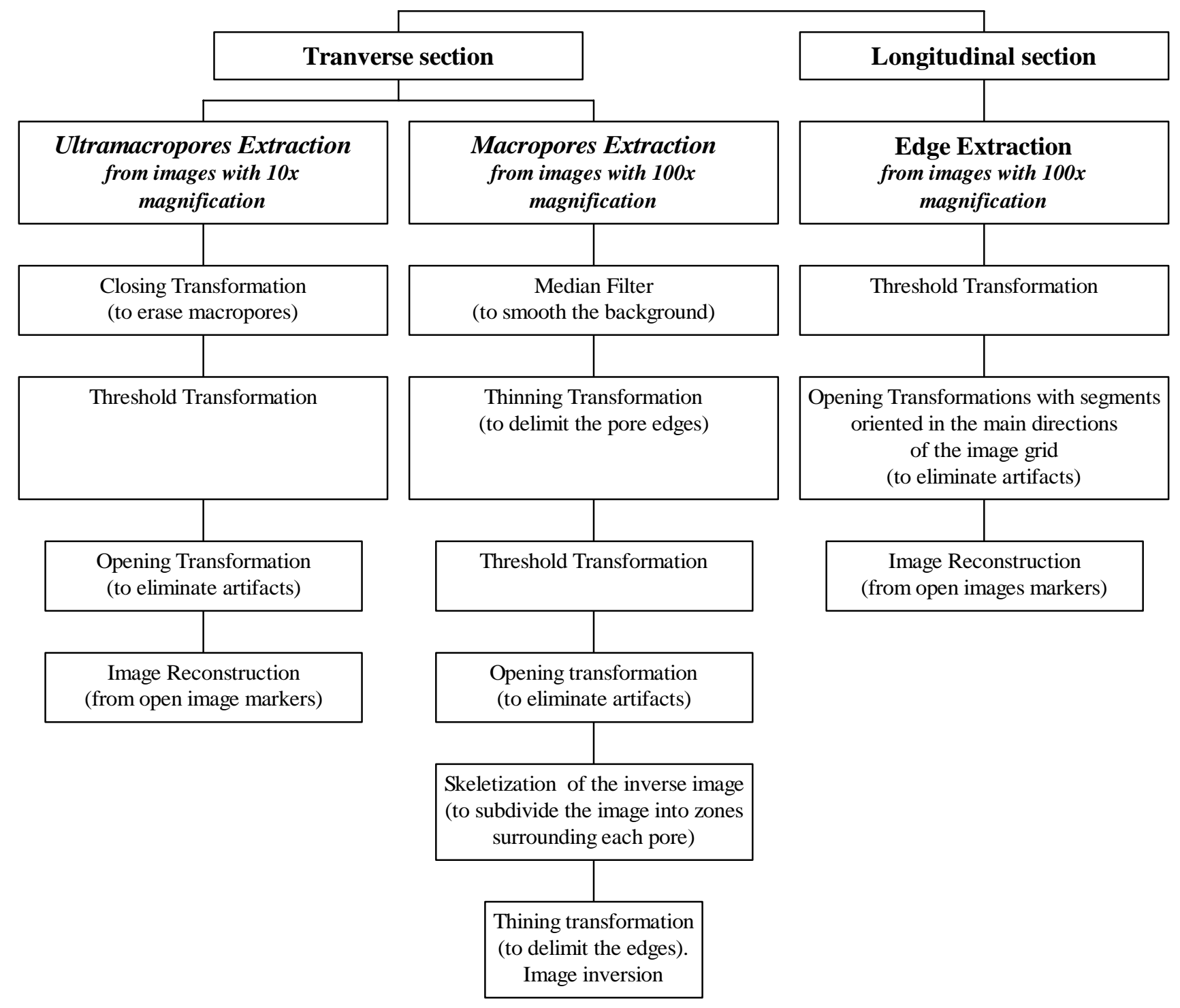

Fig. 2. Processing image binarization scheme to extract ultramacropores, macropores and pore orientations.

From transverse section images with a $10 \times$ magnification, the following characteristic sizes have been calculated: (a) the ultramacropore density $\delta_{\mathrm{M}}=$ Number of pixels characteristic of the ultramacropores/ Number of pixels of the whole image, (b) the equivalent circular diameter of the ultramacropores $D_{M}=\sqrt{4 A / \pi}$, where $A=$ Number of pixels for each pore multiplied by a calibration constant square, (c) the average distance between ultramacropores $(\bar{\lambda})$ defined as the average nearest neighbor distance, (d) the non-homogeneity of the spatial distribution of the ultramacropores (named phase $\mathrm{X}$ ) which has been underscored by the covariance function $\mathrm{C}(\mathrm{x}, \lambda)$ (Serra, 1982; Coster et al., 1985).

From transverse section images recorded with a $100 \times$ magnification, three characteristic sizes have been determined: (a) the macropore density $\delta_{\mathbf{m}}=$ Number of pixels characteristic of the macropores /Number of pixels of the whole image, (b) the shape factor $\mathrm{C}=$ Perimeter $^{2} / 4 \pi$ Area, which describes the deviation of an object from a true circle and (c) the macropore area distribution (A) instead of the equivalent circular diameter which would be irrelevant in the case of macropores with irregular shape. 
From longitudinal section images recorded with a $100 \times$ magnification, the rose of directions (Serra, 1982; Coster et al., 1985) has been used to characterize the pore orientations.

Mean values and standard deviations for $\delta_{M}, D$, $\lambda, \delta_{\mathrm{m}}, \mathrm{A}$, and $\mathrm{C}$ are reported in Table 1 for PCLA foams prepared at the two considered cooling rates. The third (sk) and the fourth (k) moments of the D and A distributions were also calculated.

Table 1 shows that the density, mean diameter and average interdistance of the ultramacropores increase with the cooling rate. Whatever of the cooling rate is, the diameter distribution of the ultramacropores follows an almost gaussian law (low values of sk and k) (see Fig. 3a). However, the maximum of the $\mathrm{D}$ distribution shifts to larger diameter when the freezing temperature was increased. Comparison of the ultra- and macropore density $\left(\delta_{M}\right.$ and $\delta_{\mathrm{m}}$ in Table 1) shows that the macropores essentially contribute to the foam porosity. The macropore area obeys a log-normal distribution (Fig. 3b). Upon increasing the freezing temperature, the A size distribution becomes more asymmetric and broader and the mean value of $A$ decreases. The macropore factor shape decreases when the cooling rate is increased indicating that macropores formed at higher cooling rate are more circular.

In order to study the state of distribution of the ultramacropores, the covariance function has been calculated (Figs. 4a-b). For both PCLA foams prepared at $-78^{\circ} \mathrm{C}$ and $-196^{\circ} \mathrm{C}$, the covariance function in the two directions $\mathrm{x}, \mathrm{y}$ does not show any significant difference. Moreover, at long distances, all curves show very damped oscillations, indicating an isotrope and almost homogeneous distribution of the ultramacropores in the polymer foam. The first local maximum at about $0.4 \mathrm{~mm}$ corresponds to the most frequent distance between two ultramacropores.

Table 1. Image analysis for PCLA foams prepared at $-78^{\circ} \mathrm{C}$ (A-78) and $-196^{\circ} \mathrm{C}$ (A-196)

\begin{tabular}{|c|c|c|c|c|c|c|}
\hline \multirow{2}{*}{$\begin{array}{l}\text { Foam } \\
\text { name }\end{array}$} & \multicolumn{3}{|c|}{ Ultramacropore characteristics } & \multicolumn{3}{|c|}{ Macropore characteristics } \\
\hline & $\delta_{M}$ & $\begin{array}{l}\mathrm{D}(\mathrm{mm}) \\
\mathrm{s}_{\mathrm{k}}, \mathrm{k}\end{array}$ & $\lambda(\mathrm{mm})$ & $\delta_{\mathrm{m}}$ & $\begin{array}{c}\mathrm{A}\left(10^{-2} \mathrm{~mm}^{2}\right) \\
\mathrm{s}_{\mathrm{k}}, \mathrm{k}\end{array}$ & $\mathrm{C}$ \\
\hline A-78 & $0.0900 \pm 0.003$ & $\begin{array}{c}0.105 \pm 0.031 \\
0.27,0.27\end{array}$ & $0.32 \pm 0.14$ & $0.53 \pm 0.07$ & $\begin{array}{c}0.233 \pm 0.230 \\
2.23,6.11\end{array}$ & $2.11 \pm 0.66$ \\
\hline A-196 & $0.130 \pm 0.005$ & $\begin{array}{c}0.194 \pm 0.066 \\
0.35,0.26\end{array}$ & $0.46 \pm 0.16$ & $0.67 \pm 0.05$ & $\begin{array}{c}0.161 \pm 0.124 \\
2.76,12.52 \\
\end{array}$ & $1.88 \pm 0.59$ \\
\hline
\end{tabular}
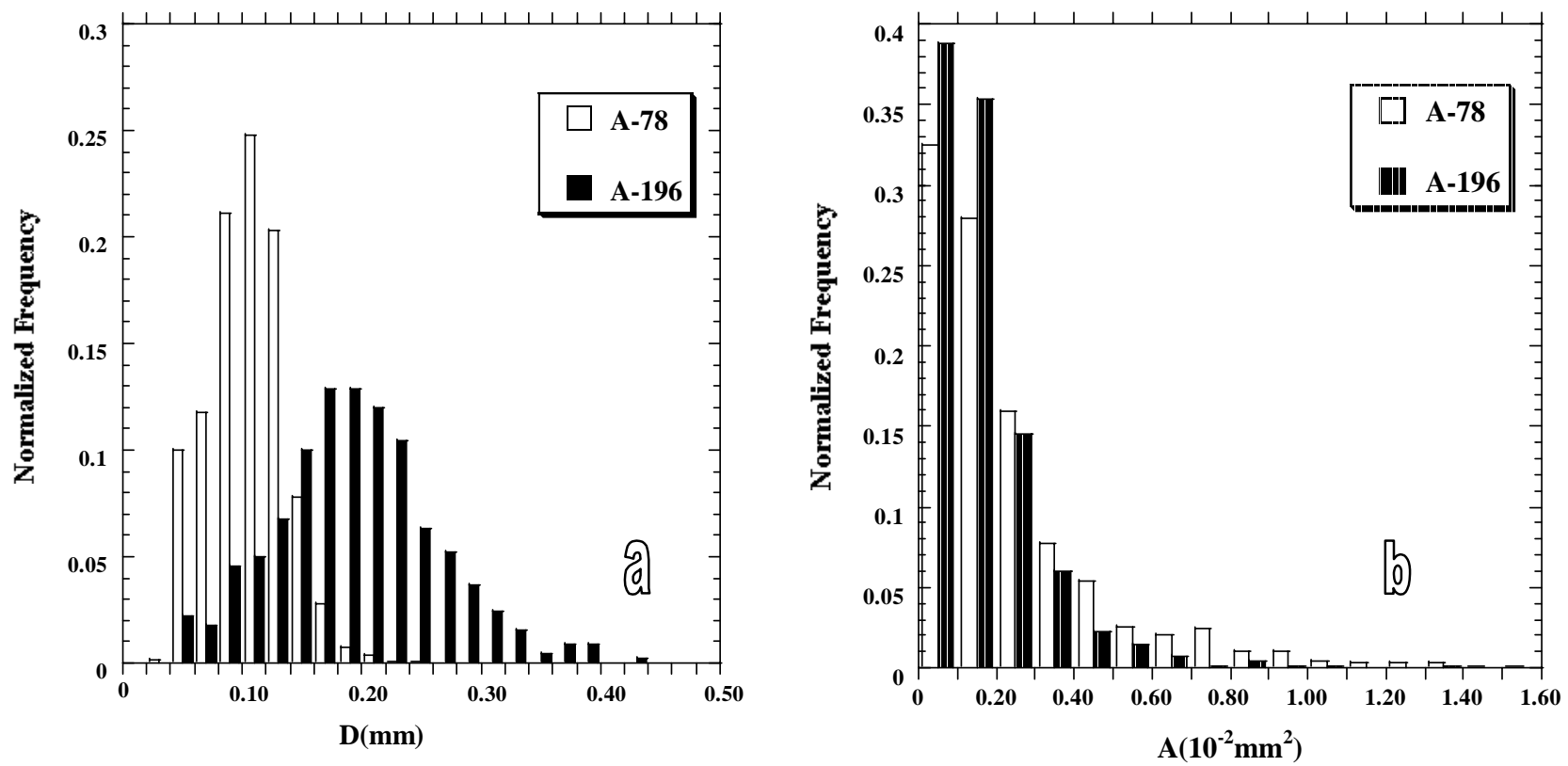

Fig. 3. (a) Diameter distribution of the ultramacropores and (b) area size distribution of the macropores. 

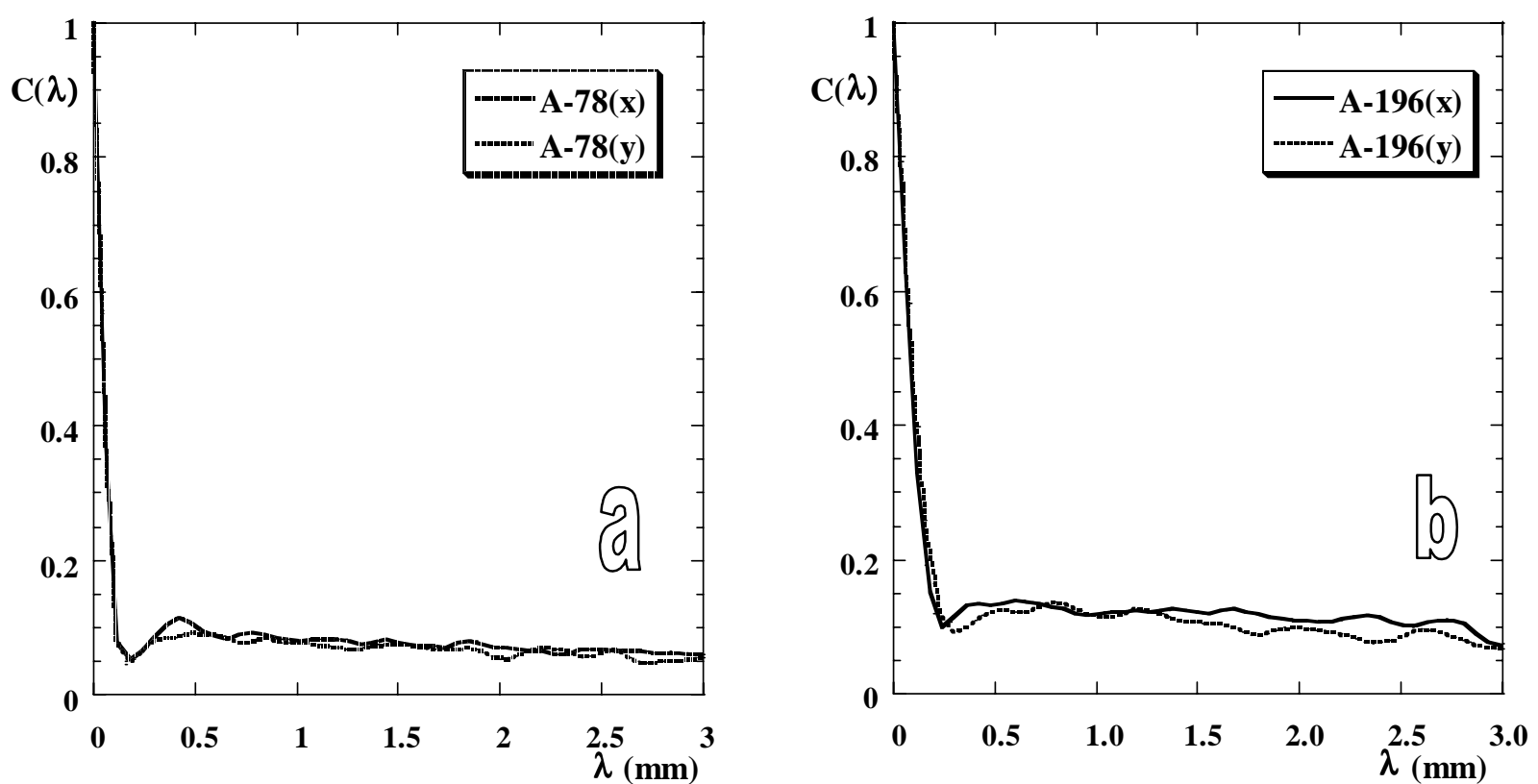

Fig. 4. Covariance function of the ultramacroporous structure, for PCLA foams prepared at $-78^{\circ} \mathrm{C}(a)$ and $196^{\circ} \mathrm{C}(b)$.

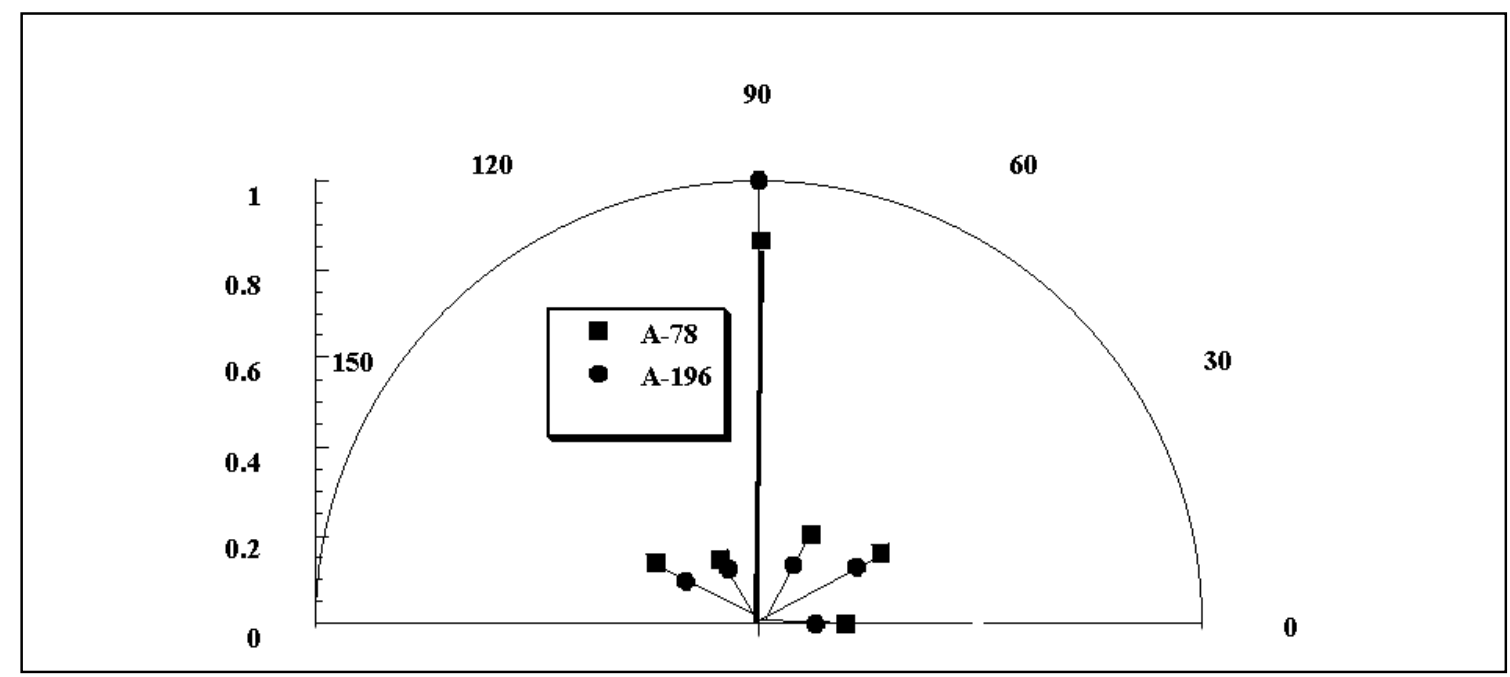

Fig. 5. Rose of directions from the longitudinal section of PCLA foams.

Fig. 5 shows the rose of directions calculated from the longitudinal sections of PCLA foams prepared at $-78^{\circ} \mathrm{C}$ and $196^{\circ} \mathrm{C}$. For the two different freezing temperatures, pore contours are mainly oriented at $\alpha=\pi / 2$ confirming that the unidirectional cooling is responsible for the orientation of the growing solvent crystals. Nevertheless, the number of pore contours having other orientation decreases with increasing cooling rate.

\section{CONCLUSION}

In this study, image processing and measurements have been developed in order to extract the pore structure of PCLA foams prepared by freeze-drying at two different cooling rates. It has been shown that image analysis actually provides valuable information on the structure of foams prepared under different 
conditions and has the advantage to be nondestructive for the pore structure. SEM images of longitudinal and transverse sections have been recorded at different magnifications. The relation between the ultramacropore and macropore size and morphology was found to be dependent on the processing parameters. Indeed, the ultramacropore size and density increase with the cooling rate, whereas the macropores become smaller and more circular. The ultramacropore distribution within the macroporous matrix is homogeneous whatever the cooling rate. A key parameter for polymer scaffold is the pore orientation, which is firstly studied in this domain. For PCLA porous foams, the higher the cooling rate, the larger the pore anisotropy.

\section{REFERENCES}

Blacher S, Maquet V, Pirard R, Pirard J-P, Jérôme R (2001). Image analysis, impedance spectroscopy and mercury porosimetry characterisation of freeze-drying porous materials. Colloids and Surfaces A: Physicochemical and Engineering Aspects 187188:375-83.
Coster M, Chermant JL (1985). Précis d'analyse d'images. Paris: CNRS.

Maquet V, Blacher S, Pirard J-P, Jérôme R (2000). Characterization of porous polylactide foams by image analysis and impedance spectroscopy. Langmuir 16:10463-70.

Maquet V, Jérôme R (1997). Design of Macroporous Biodegradable Polymer Scaffolds for Cell Transplantation In: Porous Materials for Tissue Engineering, Vol. 250. Uetikon-Zuerich: Trans Tech Publications Ltd, 15-42.

Maquet V, Martin D, Malgrange B, Franzen R, Schoenen J, Moonen G, Jérôme R (2000). Peripheral nerve regeneration using bioresorbable macroporous polylactide scaffolds. J Biomed Mat Res 52:639-51.

Maquet V, Martin D, Scholtes F, Franzen R, Schoenen J, Moonen G, Jérôme R (2001). Poly(D,L-lactide) foams modified by poly(ethylene oxide)-block-poly(D,Llactide) copolymers and a-FGF: in vitro and in vivo evaluation for spinal cord regeneration. Biomaterials 22:1137-46.

Serra J. (1982). Image analysis and mathematical morphology. New York: Academic press. 